\title{
MODIFIED QUANTIFICATION THROUGH HIGH-PERFORMANCE LIQUID CHROMATOGRAPHY ANALYSIS FOR CANAGLIFLOZIN AND METFORMIN HYDROCHLORIDE IN BULK AND TABLETS USING ECOFRIENDLY GREEN SOLVENTS
}

\section{ADITYA TRIVEDI ${ }^{* 1}$ NOOPUR DIXIT $^{2}$, D. N. JHADE ${ }^{3}$}

${ }^{1,3}$ Sri Satya Sai University of Technology and Medical Sciences, Opposite Sehore (M. P.) India, ${ }^{2}$ Siddhi Vinayaka Institute of Technology and Sciences Bilaspur C. G.

Email: aditrivedi99@yahoo.com

Received: 19 May 2017, Revised and Accepted: 22 Aug 2017

\section{ABSTRACT}

Objective: An accurate, precise, specific modified High-Performance Liquid Chromatography method was developed for the simultaneous quantification of canagliflozin and metformin in bulk and dosage forms.

Methods: A C18 column ( $250 \times 4.6 \mathrm{~mm} ; 5$ m Phenomenex) was used with mobile phase containing 0.05\% v/v triethylamine (pH 6.5): acetonitrile $(45: 55 \% \mathrm{v} / \mathrm{v})$ at $20^{\circ} \mathrm{C}$ and isocratic pump was used for elution. The flow rate was maintained at $1.2 \mathrm{ml} / \mathrm{min}$ and eluents were monitored at $215 \mathrm{~nm}$ which is evaluated by sharp peak.

Results: The retention times of canagliflozin and metformin were $3.4 \mathrm{~min}$ and $12.7 \mathrm{~min}$ respectively and showed a good linearity in the concentration range of $40-200 \mu \mathrm{g} / \mathrm{ml}$ of Canagliflozin have found a correlation coefficient of 0.999 and 10-50 $\mu \mathrm{g} / \mathrm{ml}$ of Metformin with a correlation coefficient of 0.998. The average percent recoveries were found to be $98.60 \%$ and $98.90 \%$ respectively for Canagliflozin and Metformin. The developed method follows all the validation parameters like accuracy, precision, linearity, limit of detection, limit of quantitation and solution stability.

Conclusion: The proposed method was found to provide faster retention time with sharp resolution with linearity at a lowest concentration as compared to previous methods and this method is validated as per International Conference on Harmonization guidelines and successfully applied to the simultaneous estimation of Canagliflozin and metformin in bulk and dosage forms. There was no such novel method for simultaneous estimation of Canagliflozin and metformin. Hence the developed method is suitable for industrial analysis of Canagliflozin and metformin with ecofriendly,green and less expensive solvents

Keywords: Canagliflozin, Metformin, Simultaneous estimation, Phenomenex C18 column, RP-HPLC, PDA detection, Validation

(C) 2017 The Authors. Published by Innovare Academic Sciences Pvt Ltd. This is an open access article under the CC BY license (http://creativecommons.org/licenses/by/4.0/) DOI: http://dx.doi.org/10.22159/ijap.2017v9i5.20112

\section{INTRODUCTION}

Canagliflozin inhibit SGLT2 by binding more potently (250-times) than SGLT1. The 50\% inhibitory concentrations ( IC $_{50}$ ) are 2.2-4.4 $\mathrm{nmol} / \mathrm{l}$ and $684-910 \mathrm{nmol} / \mathrm{l}$ for SGLT2 and SGLT1 respectively. Chemically Canagliflozin is $2 \mathrm{~S}, 3 \mathrm{R}, 4 \mathrm{R}, 5 \mathrm{~S}, 6 \mathrm{R}-2-\{3-[5-[4$-Fluorophenyl)-thiophen-2-ylmethyl]-4-methyl-phenyl\}-6-hydroxymethyltetrahydro-pyran-3,4,5-triol. Metformin is an oral antihyperglycemic agent that improves glucose tolerance in patients with NIDDM, lowering both basal and postprandial plasma glucose [1]. Metformin is not chemically or pharmacologically related to any other class of oral anti hyperglycemic agents [2]. Chemically it is N, NDimethylimidodicarbonimidicdiamide they are used for management of diabetes [3] UPLC method of metformin $\mathrm{HCl}$ and empagliflozin was reported earlier [4]. Literature survey reveals that few methods have been reported on an analysis of canagliflozin and metformin individually in pharmaceutical dosage forms. Also, the validated HPLC methods reported till date for the simultaneous estimation of canagliflozin and metformin does not use mobile phase $0.05 \% \mathrm{v} / \mathrm{v}$ triethylamine $(\mathrm{pH} 6.5)$ : acetonitrile $(45: 55 \% \mathrm{v} / \mathrm{v})$ at $20^{\circ} \mathrm{C}$. For elution, the flow rate was maintained at $1.2 \mathrm{ml} / \mathrm{min}$ with precise retention time and a good linearity in the small concentration range of $40-200 \mu \mathrm{g} / \mathrm{ml}$. Hence, the main objective of the present work was to develop a new method for the simultaneous analysis of canagliflozin and metformin in bulk and dosage forms [5] by using HPLC with more eco-compatible and greener solvents [6][6a].

\section{MATERIALS AND METHODS}

Reagents and chemicals

Canagliflozin and metformin were gift samples from Sun Pharma, India. Acetonitrile, water and triethylamine were purchased from E. Merck, Mumbai, India. All the solvents and reagents used were green and HPLC grade. Invokamet contains canagliflozin $50 \mathrm{mg}$ and metformin $500 \mathrm{mg}$ tablets manufactured by Janssan Pharmaceuticals were locally purchased.

\section{Equipment}

A Shimadzu Prominence HPLC system provided with DGU-20A3 degasser was used. The HPLC system consisted of a model LC-20A (Prominence) Simadzu, Japan. Data acquisition was carried out using LC solutions software. The chromatographic analysis was performed on Phenomenex C-18 column $(250 \times 4.6 \mathrm{~mm} ; 5 \mu \mathrm{m})$.

\section{Chromatographic conditions}

Mobile phase consisting of $0.05 \% \mathrm{v} / \mathrm{v}$ triethylamine of $\mathrm{pH} 6.5$ (orthophosphoric acid used to maintain the $\mathrm{pH}$ ): acetonitrile (45:55\% $\mathrm{v} / \mathrm{v}$ ). The mobile phase was filtered through Millipore nylon disc filter of $0.45 \mu \mathrm{m}$ followed by ultrasonication for $3 \mathrm{~min}$. The flow rate was maintained at $1.2 \mathrm{ml} / \mathrm{min}$ with an injection volume of $20 \mu \mathrm{l}$. Eluents were monitored at $215 \mathrm{~nm}$ and the separation was found.

\section{Preparation of stock and standard solutions}

The stock solutions of canagliflozin and metformin of concentration $1 \mathrm{mg} / \mathrm{ml}$ were prepared in $10 \mathrm{ml}$ volumetric flask using methanol as a solvent. The working standard solutions in the concentration ranging from $40-200 \mu \mathrm{g} / \mathrm{ml}$ of canagliflozin and $10-50 \mu \mathrm{g} / \mathrm{ml}$ of metformin were prepared by appropriately diluting the stock solutions with acetonitrile as diluents and kept at $20^{\circ} \mathrm{C}$.

\section{Method validation}

The method was validated according to the ICH guidelines [10].

\section{Specificity}

Canagliflozin and Metformin in pure form were evaluated by comparing the standard and sample solutions with a blank. 
Specificity is a measure of the degree of interference in the analysis of the sample mixtures into which known impurities were added. Specificity of the method was carried out by comparing chromatogram to check interference peaks.

\section{Linearity}

The aliquots of five different concentrations were evaluated across the range of the analytical procedure. A series of standard dilutions of canagliflozin and metformin were prepared over a concentration range of $40-200 \mu \mathrm{g} / \mathrm{ml}(40,80,120,160$ and $200 \mu \mathrm{g} / \mathrm{ml})$ and $10-$ $50 \mu \mathrm{g} / \mathrm{ml}(10,20,30,40$ and $50 \mu \mathrm{g} / \mathrm{ml})$ respectively from stock solutions. Peak area was determined with correspondence to the analyte concentration and the test results were evaluated by appropriate statistical methods where by slope, intercept and regression $\left(\mathrm{R}^{2}\right)$ and correlation coefficients $\left(\mathrm{r}^{2}\right)$ were calculated.

\section{Precision}

Precision was measured in the same analytical condition in terms of repeatability of procedure, application and measurement. Repeatability of the standard application was carried out using six replicates of the standard concentration of canaglilozin $(80 \mu \mathrm{g} / \mathrm{ml})$ and metformin $(20 \mu \mathrm{g} / \mathrm{ml})$. Peak area is indicated less than $2 \%$ RSD which indicates the precision of the method.

\section{Accuracy}

The accuracy of this method was found in the whole analytical procedure. Accuracy (recovery) of the method was tested by spiking 80,100 and $120 \%$ of canagliflozin $(80 \mu \mathrm{g} / \mathrm{ml})$ and metformin $(20 \mu \mathrm{g} / \mathrm{ml})$ standard concentrations. These solutions were analyzed by a developed method in triplicate. The calculation of \%RSD and \% recovery was done throughout the addition level.

\section{Robustness}

In this method by changing the flow rate and wave length the result withstand rigorous testing. The HPLC parameters like capacity factor, tailing factor, theoretical plate number and \% assay were observed. The flow rate of the mobile phase was maintained at 1.2 $\mathrm{ml} / \mathrm{min}$. To prove the robustness of this method, the flow rate was changed by $\pm 20 \%$ and wavelength by $\pm 5 \mathrm{~nm}$.

\section{Limit of detection and quantification}

Calibration curve method was used to determine LOD and LOQ. Standard solutions of canagliflozin and metformin were prepared in the range of $40-200 \mu \mathrm{g} / \mathrm{ml}$ and $10-50 \mu \mathrm{g} / \mathrm{ml}$ injected $(20 \mu \mathrm{l})$ in triplicate. The average peak area of two drugs was plotted against concentration. LOD and LOQ were calculated by using following equations:

$$
\mathrm{LOD}=(3.3 \times \sigma) / \mathrm{m} ; \mathrm{LOQ}=(10.0 \times \sigma) / \mathrm{m}
$$

\section{System suitability}

System suitability was carried out by injecting a standard concentration $(40 \mu \mathrm{g} / \mathrm{ml}$ of canagliflozin and $10 \mu \mathrm{g} / \mathrm{ml}$ of metformin) at different injection volumes in the range of 10-50 $\mu \mathrm{l}$ and \% RSD was calculated.

\section{Assay}

Of the combined dosage forms presently available in the market, canagliflozin (containing $50 \mathrm{mg}$ ) and metformin (containing 500 $\mathrm{mg}$ ) were used in these studies. Powder blend (10 tablets of each brand) equivalent to $10 \mathrm{mg}$ of Canagliflozin and Metformin were separately weighed and transferred to a $10 \mathrm{ml}$ volumetric flask. $5 \mathrm{ml}$ of methanol was added followed by sonication for $5 \mathrm{~min}$ and volume was made up to the mark with methanol. The solutions were centrifuged and the supernatant were filtered using syringe filter $(13 \mathrm{~mm}, 0.45 \mu \mathrm{m})$. Aliquots of the drugs of concentration $80 \mu \mathrm{g} / \mathrm{ml}$ and $20 \mu \mathrm{g} / \mathrm{ml}$ of Canagliflozin and Metformin were prepared and analyzed in triplicates. The amount present in each tablet was calculated by comparing the areas of standard Canagliflozin and Metformin with that of the sample.

\section{RESULTS AND DISCUSSION}

\section{Validation of the chromatographic conditions}

The present work was carried out with a view for development of ecofriendly green HPLC method for the simultaneous estimation of canagliflozin and metformin in bulk and dosage forms. Initial trials were carried out with Phenomenex C-18 column (250 x $4.6 \mathrm{~mm}$; 5 $\mu \mathrm{m})$ using mobile phase $0.05 \% \mathrm{v} / \mathrm{v}$ formic acid and methanol $(60: 40 \% \mathrm{v} / \mathrm{v})$ at a flow rate of $1.2 \mathrm{ml} / \mathrm{min}$ and acetonitrile as the diluents. The quantification was carried out at $215 \mathrm{~nm}$. Under these conditions, canagliflozin was eluted at $3.16 \mathrm{~min}$ and metformin at $4.88 \mathrm{~min}$. The canagliflozin was almost eluted with the solvent front. In the other modification trial, methanol was replaced with acetonitrile and mobile phase combination of $80: 20 \% \mathrm{v} / \mathrm{v}$ was used and kept at $20^{\circ} \mathrm{C}$. At a flow rate of $1.2 \mathrm{ml} / \mathrm{min}$ the elution time for canagliflozin was $3.61 \mathrm{~min}$ and metformin was $6.70 \mathrm{~min}$. However, the resolution between the solvent front and the canagliflozin peak was not prominent. Then, $0.05 \% \mathrm{v} / \mathrm{v}$ triethylamine was taken (adjusted to $\mathrm{pH} 6.5$ with orthophosphoric acid) with acetonitrile in the ratio of $50: 50 \% \mathrm{v} / \mathrm{v}$ and the flow rate was $1.2 \mathrm{ml} / \mathrm{min}$. Under these conditions, the canagliflozin was eluted at $5.14 \mathrm{~min}$ and Metformin at a longer retention of $20.23 \mathrm{~min}$. Finally, the ratio of the mobile phase changed to $45: 55 \% \mathrm{v} / \mathrm{v}$ of $0.05 \% \mathrm{v} / \mathrm{v}$ triethylamine and acetonitrile. The flow rate of $1.2 \mathrm{ml} / \mathrm{min}$ is maintained in order to achieve a proper resolution of both canagliflozin and metformin peaks respectively. Under these conditions, the canagliflozin and metformin peaks were eluted at $3.47 \mathrm{~min}$ and $12.34 \mathrm{~min}$ respectively. Symmetrical peaks were found and the tailing factor was within the limits. For quantitative analytical purpose wavelength was set at 215 $\mathrm{nm}$, which provided better reproducibility without interference. The peak purity was found to be greater than 0.9999 for both the drugs, canagliflozin and metformin used in the analysis. A sample chromatogram of canagliflozin and metformin were given in fig. 1 along with UV spectra.

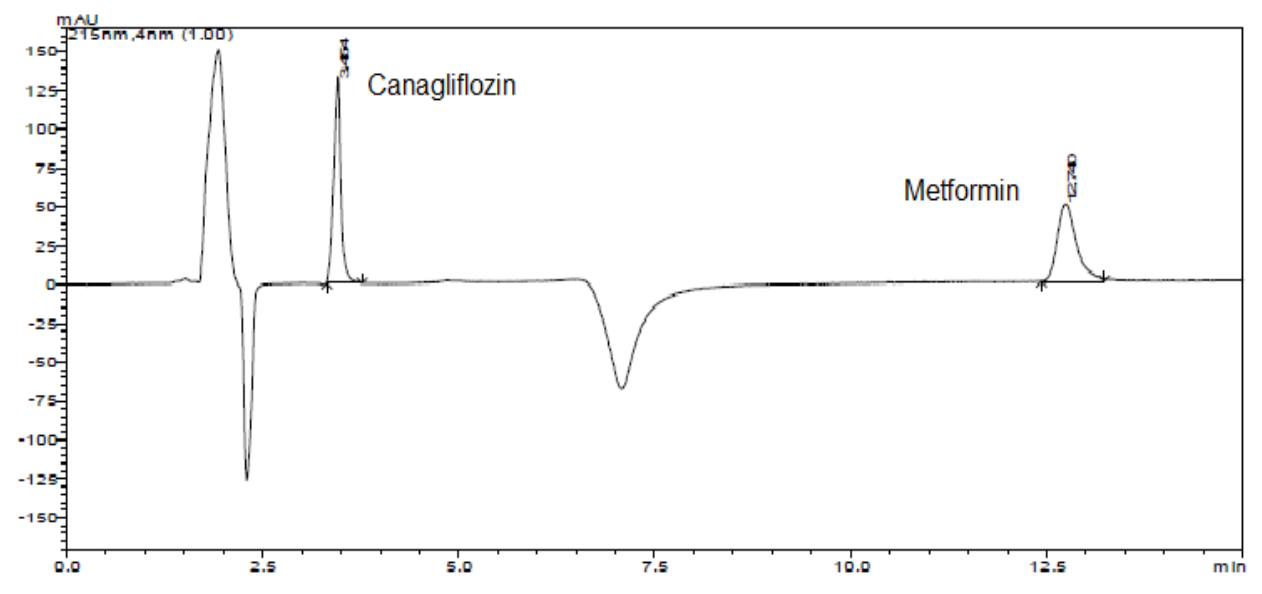




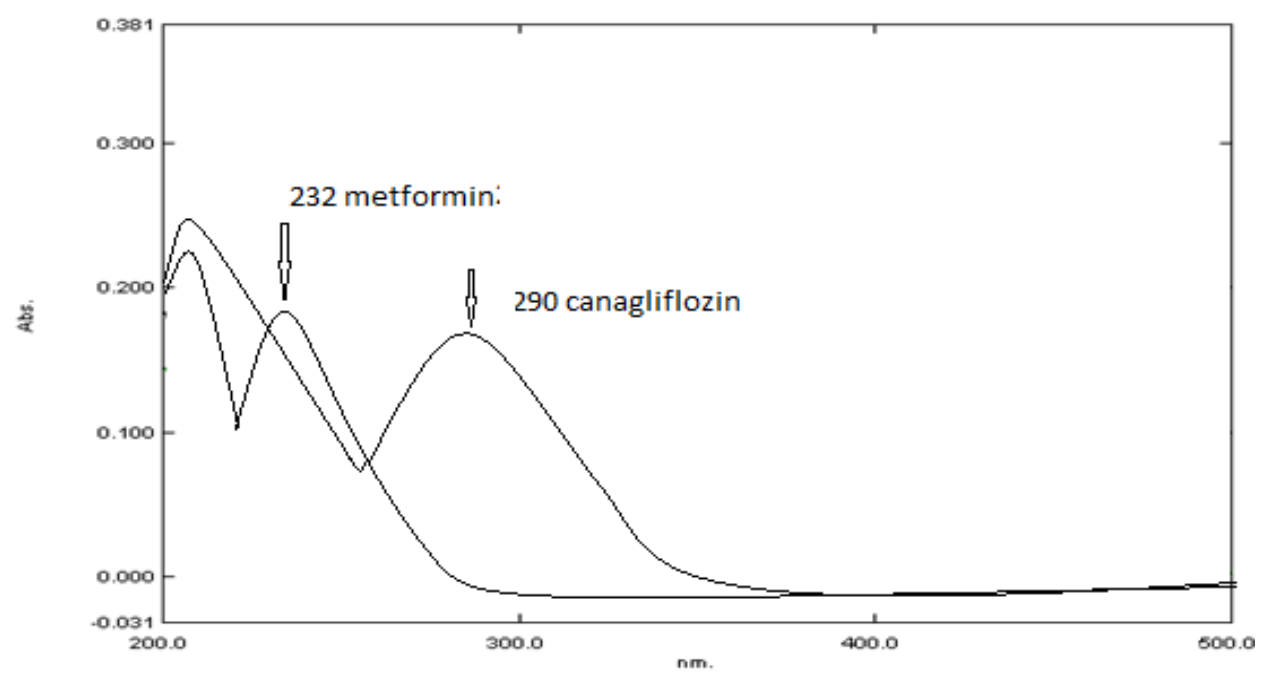

Fig. 1: Standard chromatogram of canagliflozin $(40 \mu \mathrm{g} / \mathrm{ml})$ and metformin $(20 \mu \mathrm{g} / \mathrm{ml})$ mixture (A); and (B) overlay UV spectra of canagliflozin and metformin

\section{Method validation}

\section{Specificity}

The specificity of this modified eco-friendly green method was established by using solutions of diluents, placebo, standard and test sample (Tablets). The inference from the 3D plots of placebo and test samples, shown in fig. 2, proves that there were no co-eluting peaks at the retention time of canagliflozin and metformin. The results showed that peak of drug candidate was pure and the excipients in the formulation did not interfere with the analysis. The purity of peak for sample and standard were found to be greater than 0.9999 , hence the method confirms specificity.

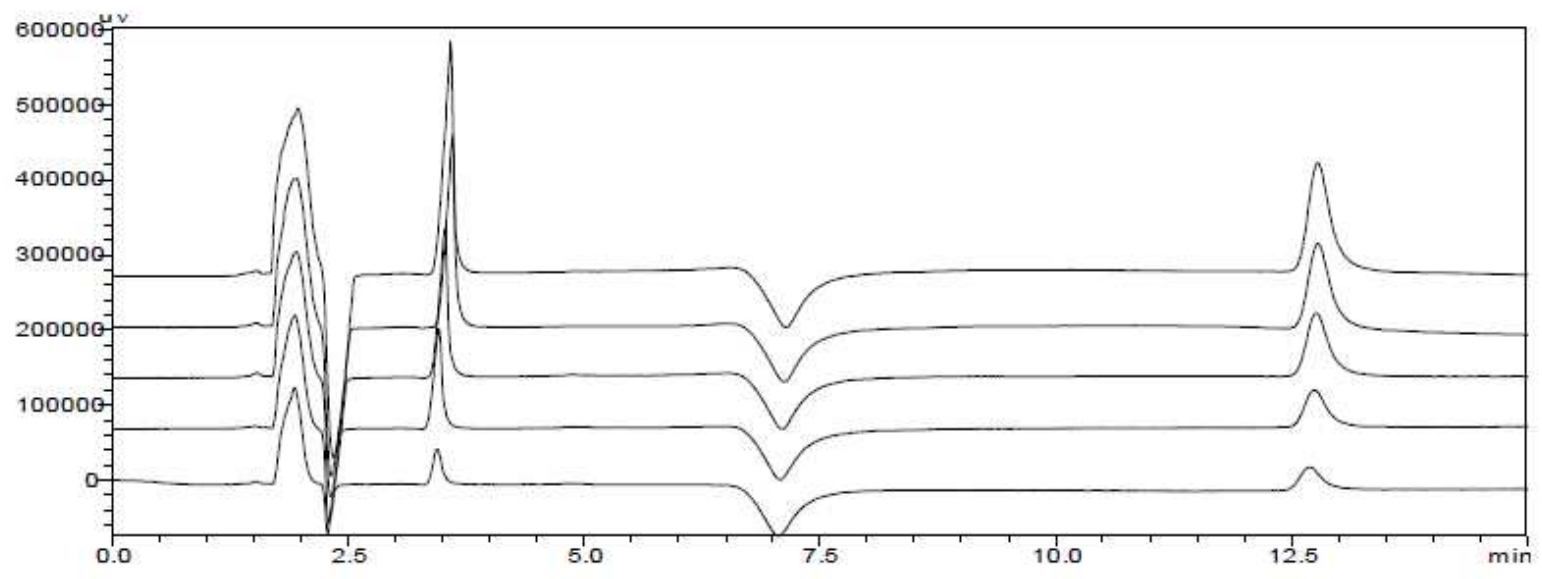

Fig. 2: Overlaid canagliflozin $(40-200 \mu \mathrm{g} / \mathrm{ml})$ and metformin $(10-50 \mu \mathrm{g} / \mathrm{ml})$ standard chromatograms

\section{Linearity}

A linear relationship evaluated across a concentration range 40$200 \mu \mathrm{g} / \mathrm{ml}$ of canagliflozin and $10-50 \mu \mathrm{g} / \mathrm{ml}$ of metformin in triplicates $(\mathrm{n}=3)$. The concentration range was selected based on 80,100 and $120 \%$ of the test concentration for assay.

Peak area and concentration data were subjected to least square regression analysis. The correlation coefficients (R) were found to be 0.999 and 0.998 respectively for canagliflozin and metformin and indicate a good linearity within the concentration range selected. The data of the calibration curve was given in table 1 and chromatograms were shown in fig 2.

\section{Precision}

Precision studies were carried out in terms of repeatability. Repeatability of standard application was assessed by using six replicates of concentration at $80 \mu \mathrm{g} / \mathrm{ml}$ of canagliflozin and $20 \mu \mathrm{g} / \mathrm{ml}$ of metformin and the data was given in Table-2. The \% RSD was found to be less than 2 for peak areas; this shows the closeness of the data values to each other, indicating the method was précised.

\section{Accuracy}

Accuracy of the proposed method was ascertained by performing recovery studies using the standard addition method by spiking the known quantities of standards at 80,100 , and $120 \%$ to the test solution of $80 \mu \mathrm{g} / \mathrm{ml}$ of canagliflozin and $20 \mu \mathrm{g} / \mathrm{ml}$ of metformin. The analyte peak is evaluated by 3D plots of the chromatogram in order to confirm the existence of components at $3.4 \mathrm{~min}$ and $12.7 \mathrm{~min}$ elution time of canagliflozin and metformin respectively and shown in fig. 3. The recoveries were found to be $99.15-101.73 \%$, 99.04$100.04 \%$, and $98.24-99.50 \%$ at 80,100 and $120 \%$ respectively for canagliflozin and metformin. These results indicate a good accuracy of the method to that of the labelled claim. The obtained recovery results were given in table 1 . 
Table 1: Linearity, accuracy and precision data

\begin{tabular}{|c|c|c|c|}
\hline Validation parameters & Parameters & Canagliflozin & Metformin \\
\hline \multirow[t]{4}{*}{ Linearity $(\mathrm{n}=3)$} & Range & $40-200 \mu \mathrm{g} / \mathrm{ml}$ & $10-50 \mu \mathrm{g} / \mathrm{ml}$ \\
\hline & Regression equation & $Y=11632 x-1152$ & $Y=53152 x-7026$ \\
\hline & Regression coefficient $\left(\mathrm{R}^{2}\right)$ & 0.999 & 0.998 \\
\hline & Correlation coefficient $\left(\mathrm{r}^{2}\right)$ & 0.998 & 0.997 \\
\hline \multirow[t]{4}{*}{$\operatorname{Accuracy}(n=3)$} & $\%$ Level of addition & Mean $\% \pm$ recovery(RSD) & Mean $\% \pm$ recovery(RSD) \\
\hline & 80 & $99.59 \pm(1.95)$ & $100.03 \pm(1.08)$ \\
\hline & 100 & $99.12 \pm(0.89)$ & $101.07 \pm(1.02)$ \\
\hline & 120 & $99.82 \pm(0.64)$ & $100.09 \pm(0.86)$ \\
\hline \multicolumn{4}{|l|}{ Precision $(n=6)$} \\
\hline System precision & Average peak area of the standard sample (RSD) & $839193 \pm(1.94)$ & $9404 \pm(1.13)$ \\
\hline Method precision & Average peak area of the Assay sample (RSD) & $855010 \pm(0.81)$ & $8891 \pm(0.16)$ \\
\hline
\end{tabular}

For Linearity and Accuracy n = 3 Mean \% \pm recovery (RSD) and for Precision $n=6$ Mean \% \pm recovery (RSD)

\section{Robustness}

As part of the robustness, a deliberate change in the flow rate and wavelength was made to evaluate the impact on the method. Significant change in retention time was found with flow rate and showed no change with wavelength. Moreover \% assay values were within limits and these results indicated minor changes in the flow rate but wavelength didn't affected the assay results. The results were given in table 2 .

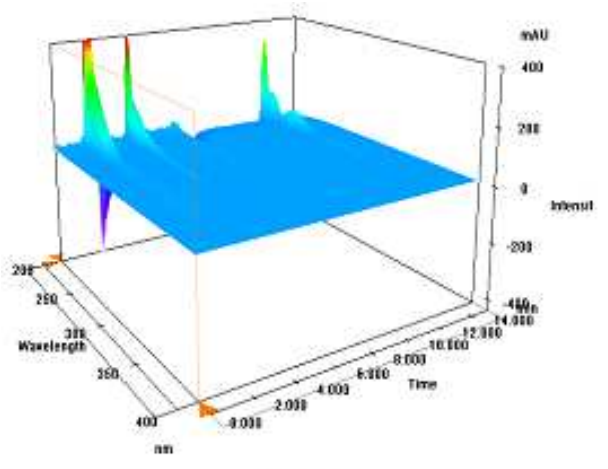

\section{3 d chromatogram of sample}

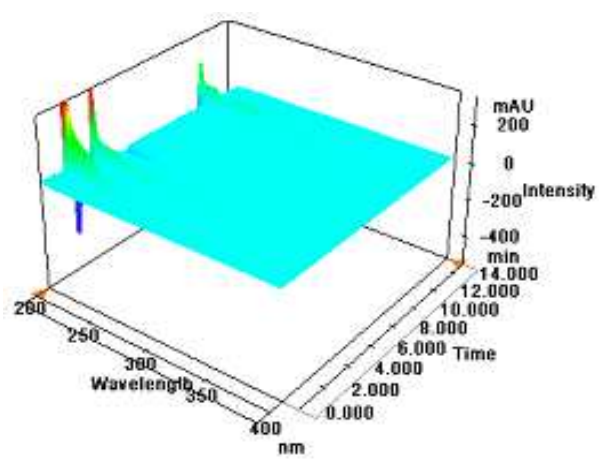

3D chromatogram of standerd

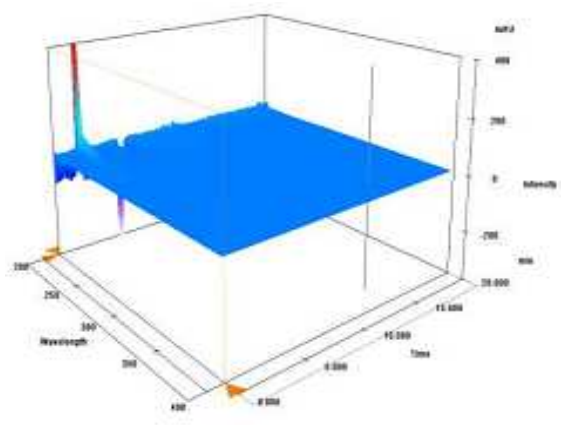

\section{$3 \mathrm{~d}$ chromatogram of diluent} solution

Fig. 3: 3D plots of sample standard and diluents

\section{Detection and quantification limits}

LOD and LOQ were calculated from the average slope and standard deviation from the calibration curve. LOD for canagliflozin and metformin was found to be 0.326 and $0.436 \mathrm{mg} / \mathrm{ml}$ respectively. LOQ for canagliflozin and metformin was found to be 0.990 and $1.321 \mathrm{mg} / \mathrm{ml}$ respectively.

\section{System suitability}

System suitability studies were carried out by injecting a $40 \mathrm{mg} / \mathrm{ml}$ standard of canagliflozin and $10 \mu \mathrm{g} / \mathrm{ml}$ of metformin respectively at injection volumes ranging from 10-50 $\mu \mathrm{L}$. With increment of injection volumes, the \% RSD for tailing factor and theoretical plate number were calculated and were found to be within limits.

\section{Assay}

Assay of canagliflozin and metformin in tablets was performed by the proposed method and the $\%$ assay was calculated as an average of 3 determinations. These results indicate that the present HPLC method is quite eco friendly using green solvents successfully for the simultaneous assay of canagliflozin and metformin respectively in bulk and dosage forms. The assay values were found to be within the limits and the data was given in table 4 .

Table 2: Robustness data for wavelength

\begin{tabular}{lllllll}
\hline Drug & Parameter range & Retention time in min. & Theoretical plates (N) & Tailing factor & Capacity factor (k) & \% assay \\
\hline Canagliflozin & 210 & 3.5 & 5274.5 & 1.0 & 1.1 & \\
& 215 & 3.54 & 6079.5 & 1.0 & 0.8 & 10.5 \\
\multirow{4}{*}{ Metformin } & 220 & 3.5 & 5317.1 & 1.3 & 0.8 & 100.3 \\
& 210 & 12.7 & 14152.6 & 1.4 & 5.6 & 101.2 \\
& 215 & 12.7 & 14886.4 & 1.3 & 5.6 & 100.3 \\
\hline
\end{tabular}

$\mathrm{n}=3$ 
Table 3: Robustness data for flow rate

\begin{tabular}{|c|c|c|c|c|c|c|}
\hline Drug & Parameter range & Retention time in min & Theoretical plates $(\mathrm{N})$ & Tailing factor & Capacity factor (k) & \% assay \\
\hline \multirow[t]{3}{*}{ Canagliflozin } & 1.0 & 4.5 & 5282.3 & 1.42 & 0.99 & 98.6 \\
\hline & 1.2 & 3.7 & 4895.4 & 1.37 & 0.94 & 101.2 \\
\hline & 1.4 & 3.4 & 4906.2 & 1.39 & 1.1 & 99.8 \\
\hline \multirow[t]{3}{*}{ Metformin } & 1.0 & 13.8 & 13827.6 & 1.47 & 5.54 & 101.8 \\
\hline & 1.2 & 12.7 & 13040.7 & 1.39 & 5.62 & 100.2 \\
\hline & 1.4 & 11 & 13633.8 & 1.38 & 5.79 & 98.2 \\
\hline
\end{tabular}

$\mathrm{n}=3$

Table 4: Assay of formulation

\begin{tabular}{lllll}
\hline Formulation & Drug & Labled claim in mg & Amount found mean \pm SD & \% assay \\
\hline Invokamet & Canagliflozin & $50 \mathrm{mg}$ & $47.69 \pm 0.11$ & 98.2 \\
& Metformin & $500 \mathrm{mg}$ & $498.51 \pm 0.34$ & 1.19 \\
\hline
\end{tabular}

mean \pm SD and mean $\pm \%$ RSD

\section{Stability of the stock solution}

The stability of the stock solution was determined by analyzing the samples under refrigeration $\left(8 \pm 1{ }^{\circ} \mathrm{C}\right)$ at different time intervals up to $48 \mathrm{~h}$. The \% variation in assay values at different time intervals were found 0.825 for canagliflozin and 0.546 for metformin from the initial zero time interval solution, thus indicating that the solutions were stable for a period of $48 \mathrm{~h}$ when stored at $8 \pm 1^{\circ} \mathrm{C}$.

\section{DISCUSSION}

The retention times of canagliflozin and metformin were $3.4 \mathrm{~min}$ and $12.7 \mathrm{~min}$ respectively. The correlation coefficient of Canagliflozin was found to be 0.999 and Metformin 0.998. In comparison to other published methods, this environmental friendly method shows linearity in low concentration range of $40-200 \mu \mathrm{g} / \mathrm{ml}$ and $10-50 \mu \mathrm{g} / \mathrm{ml}$ of canagliflozin and metformin respectively [8]. The average percentage recoveries were found to be $98.60 \%$ and $98.90 \%$ respectively for canagliflozin and metformin which is better than the earlier publications. The eco-compatible developed method follows all the validation parameters like accuracy, precision, linearity, limit of detection, limit of quantitation and solution stability when compared to other established works [9].

\section{CONCLUSION}

The proposed HPLC method provides increased sensitivity when compared to other published HPLC methods. It is validated as per International Conference on Harmonization (ICH) Guidelines and can be used as quality control analysis for the simultaneous estimation of canagliflozin and metformin using isocratic mode of elution. The results of linearity, precision, accuracy and specificity proved to be within the limits. The method provides selective and simultaneous quantification of canagliflozin and metformin without interferences from diluents and placebo. Overall, the proposed method is highly sensitive, reproducible, reliable, rapid specific and eco-friendly employed in quality control for simultaneous estimation of canagliflozin and metformin in bulk and in dosage forms that will be available in near future in the market.

\section{CONFLICT OF INTERESTS}

Declared none

\section{REFERENCES}

1. Schernthaner G, Gross JL, Rosenstock J, Guarisco M, Fu M, Yee J, et al. Canagliflozin compared with sitagliptin for patients with type 2 diabetes who do not have adequate glycemic control with metformin plus sulfonylurea. Diabetes Care 2013; 36:2508-15.

2. Ningrum VDA, Ikawati Z, Sadewa AH, Ikhsan MR, Saepudin S. Steady-state pharmacokinetics of metformin in obese patients with type 2 diabetes mellitus: a preliminary study. Asian J Phrm Clini Res 2017;10:294-8.

3. Nisly Sarah A, Denise M, K Alison MW. Canagliflozin, a new sodium-glucose cotransporter 2 inhibitor, in the treatment of diabetes. Am J Health Syst Pharm 2013;70:311-9.

4. Madana Gopal N, Sridhar C. A validated stability indicating a ultra-performance liquid chromatographic method for simultaneous determination of metformin hydrochloride and empagliflozin in bulk drug and tablet dosage form. Int J Appl Pharm 2017;9:45-50.

5. Wiernsperger NF, Clifford JB. The antihyperglycemic effect of metformin. Drugs 1999;58 Suppl 1:31-9.

6. Khasim Sharif Sd, Radha Sirija M, Ramudu B, Ramachandran D. Green synthesis of tetrahydropyranyl ethers of phenols in the presence of triethylamine in water as a solvent. IORS J Appl Chem 2015;8:20-5

6(a) Ibrahim F, Asmaa Kamal, El-Deen Samah, Abo El Abass, Kuniyoshi Shimizu. An eco-friendly green liquid chromatographic method for simultaneous determination of nicotinamide and clindamycin phosphate in the pharmaceutical gel for acne treatment. J Food Drug Anal 2016. http://dx.doi.org/10.1016/j.jfda.2016.09.009

7. International Conference on Harmonization of Technical Requirements for the Registration of Pharmaceuticals for Human Use Validation of analytical procedure: Methodology. ICH Q2(R1). Geneva 1996;4:1-10.

8. Suneetha D, Sharmila A. Validated stability indicating a RPHPLC method for estimation of canagliflozin in the dosage form. Res J Pharm Biol Chem Sci 2015;6:1186-94.

9. Ishpreet K, Sharad W, Harsharan PS, Satish M. Development and validation of a stability-indicating reverse phase HPLCPDA method for determination of canagliflozin in bulk and pharmaceutical dosage form. Pharm Methods 2016; 7:54-62.

10. Snyder LR, Joseph JK, Joseph LG, Practical HPLC method development. John Wiley Sons 2012;2:42-9.

11. Shabir GA. Validation of high-performance liquid chromatography methods for pharmaceutical analysis: Understanding the differences and similarities between validation requirements of the US food and drug administration, the US pharmacopeia and the International Conference on Harmonization. J Chrom A 2003;987:57-66.

12. Chandran S, Singh RSP. Comparison of various international guidelines for analytical method validation. Die Pharmazie Int J Pharm Sci 2007;62:4-14.

\section{How to cite this article}

- $\quad$ Aditya Trivedi, Noopur Dixit, DN Jhade. Modified quantification through high-performance liquid chromatography analysis for canagliflozin and metformin hydrochloride in bulk and tablets using ecofriendly green solvents. Int J Appl Pharm 2017;9(5):97-101. 